\title{
Supporting materials of
}

"Substituent effect on two-dimensional assembling and chain folding of rigid-rod polymer poly-( $p$-phenyleneethynylene) derivatives on the solid/liquid interface" Sheng-Bin Lei et al

Synthesis of Monomers and Polymers. The synthetic routes for polymer 1-4 are shown in Scheme 1. The monomers of polymer 4 and its polymerization procedure have been published in the literature. [Fan, Q. L.; Zhou, Y.; Lu, X. M.; Hou, X. Y.; Huang, W. Macromolecules 2005, 38, 2927-2936]

1,4-Dihexyloxybenzene (M1). A suspension of powdered $\mathrm{KOH}(50.0 \mathrm{~g}, 0.9 \mathrm{~mol})$ and anhydrous ethanol (400 mL) was stirred and degassed at room temperature for $30 \mathrm{~min}$. Hydroquinone $(38.5 \mathrm{~g}, 0.35 \mathrm{~mol})$ in anhydrous ethanol $(150 \mathrm{~mL})$ was added dropwise. To the stirred mixture, bromohexane $(148.0 \mathrm{~g}, 0.9 \mathrm{~mol})$ in anhydrous ethanol $(50 \mathrm{~mL})$ was added. After stirring for $24 \mathrm{~h}$ with heating at reflux, the ethanol was evaporated at reduced pressure. The brownish residue was poured into water $(500 \mathrm{~mL})$ and extracted with ethyl acetate twice. The combined ethyl acetate layer was washed with water, brine, and dried over anhydrous magnesium sulfate. The white product (74.0 g, 76\%) was obtained by recrystallization from ethanol after ethyl acetate was removed under reduced pressure. MS m/z: 278. ${ }^{1} \mathrm{H}$ NMR (400 MHz, $\left.\mathrm{CDCl}_{3}\right): \delta 6.82(\mathrm{~s}, 4 \mathrm{H}), 3.90(\mathrm{t}$, $4 \mathrm{H}), 1.80-1.70(\mathrm{~m}, 4 \mathrm{H}), 1.46-1.30(\mathrm{~m}, 12 \mathrm{H}), 0.90(\mathrm{t}, 6 \mathrm{H}) .{ }^{13} \mathrm{C} \mathrm{NMR}\left(100 \mathrm{MHz}, \mathrm{CDCl}_{3}\right)$ : $\delta 153.2,115.4,68.7,31.7,29.4,25.8,22.7,14.1$.

1,4-Dihexyloxy-2,5-diiodobenzene (M2). To a solution of M1 (11.1 g, 0.04 mol), 90 $-\mathrm{S} 1-$ 
$\mathrm{mL}$ of acetic acid, $7 \mathrm{~mL}$ of water, and $3 \mathrm{~mL}$ of concentrated $\mathrm{H}_{2} \mathrm{SO}_{4}, \mathrm{KIO}_{3}(10.3 \mathrm{~g}$, $0.048 \mathrm{~mol})$ and $\mathrm{I}_{2}(13.1 \mathrm{~g}, 0.048 \mathrm{~mol})$ were added. The reaction mixture was stirred at $80{ }^{\circ} \mathrm{C}$ for $24 \mathrm{~h}$ and then cooled to room temperature. After most of the acetic acid was evaporated under reduced pressure, aqueous $\mathrm{Na}_{2} \mathrm{SO}_{3}(20 \%)$ was added until the brown color of iodine had disappeared. The mixture was poured into ice water with $\mathrm{Na}_{2} \mathrm{CO}_{3}$ $(500 \mathrm{~mL})$ and extracted with hexane $(3 \times 100 \mathrm{~mL})$. The combined organic layer was washed with water and brine and dried over $\mathrm{MgSO}_{4}$. The solvent was evaporated under reduced pressure to give a yellow solid. The white crystals $(12.7 \mathrm{~g}, 60 \%)$ were obtained by recrystallization from ethanol. MS $m / z: 530 .{ }^{1} \mathrm{H}$ NMR (400 MHz, $\mathrm{CDCl}_{3}$ ): $\delta 7.17(\mathrm{~s}, 2 \mathrm{H}), 3.92(\mathrm{t}, 4 \mathrm{H}), 1.84-1.75(\mathrm{~m}, 4 \mathrm{H}), 1.55-1.34(\mathrm{~m}, 12 \mathrm{H}), 0.91(\mathrm{t}, 6 \mathrm{H}) .{ }^{13} \mathrm{C}$ NMR (100 MHz, $\left.\mathrm{CDCl}_{3}\right): \delta 152.9,122.8,86.3,70.3,31.4,29.1,25.7,22.5,14.0$.

1,4-Bis[(trimethylsilyl)ethynyl]-2,5-bis(hexyloxy)benzene (M3). To a solution of M2 (7.95 g, $0.015 \mathrm{~mol}), \mathrm{CuI}(0.14 \mathrm{~g}, 0.75 \mathrm{mmol})$, and $\mathrm{Pd}\left(\mathrm{PPh}_{3}\right)_{2} \mathrm{Cl}_{2}(0.53 \mathrm{~g}, 0.75$ $\mathrm{mmol}$ ) in $100 \mathrm{~mL}$ of diisopropylamine was added (trimethylsilyl)acetylene (2.94 g, $0.03 \mathrm{~mol})$. The mixture was stirred at reflux for $1 \mathrm{~h}$. After cooling, dichloromethane $(100 \mathrm{~mL})$ was added, and the white ammonium iodide precipitate was filtered off. The solution was passed through a short silica gel column using toluene as eluent. After the solvent was evaporated under reduced pressure, the white crystals $(6.3 \mathrm{~g}, 89 \%)$ were obtained by recrystallization from ethanol. MS m/z: 470. ${ }^{1} \mathrm{H}$ NMR (400 MHz, $\left.\mathrm{CDCl}_{3}\right)$ : $\delta 6.88(\mathrm{~s}, 2 \mathrm{H}), 3.93(\mathrm{t}, 4 \mathrm{H}), 1.81-1.76(\mathrm{~m}, 4 \mathrm{H}), 1.53-1.33(\mathrm{~m}, 12 \mathrm{H}), 0.88(\mathrm{t}, 6 \mathrm{H}), 0.25$ (s, 18H). ${ }^{13} \mathrm{C}$ NMR $\left(100 \mathrm{MHz}, \mathrm{CDCl}_{3}\right): \delta 154.4,117.7,114.4,101.5,100.4,69.9,32.0$, $29.7,26.1,23.0,14.4,0.33$. 
1,4-Bis(ethynyl)-2,5-bis(hexyloxy)benzene (M4). M3 (2.82 g, $0.006 \mathrm{~mol})$ was dissolved in a mixture of methanol $(30 \mathrm{~mL})$, THF $(20 \mathrm{~mL})$ and $\mathrm{NaOH}(2 \mathrm{~mL}, 5 \mathrm{~N}$ in water) and stirred at room temperature for $1 \mathrm{~h}$. After evaporation of the solvent, the mixture was poured into $100 \mathrm{~mL}$ of water and extracted with hexane twice. The combined hexane layer was washed with water and brine and dried over anhydrous magnesium sulfate. The pale yellow solid (1.82 g, 93\%) was obtained after the solvent

was removed. MS m/z: 326. ${ }^{1} \mathrm{H} \mathrm{NMR}\left(400 \mathrm{MHz}, \mathrm{CDCl}_{3}\right): \delta 6.95(\mathrm{~s}, 2 \mathrm{H}), 3.97(\mathrm{t}, 4 \mathrm{H})$, $3.33(\mathrm{~s}, 2 \mathrm{H}), 1.84-1.75(\mathrm{~m}, 4 \mathrm{H}), 1.50-1.26(\mathrm{~m}, 12 \mathrm{H}), 0.90(\mathrm{t}, 6 \mathrm{H}) .{ }^{13} \mathrm{C} \mathrm{NMR}(100 \mathrm{MHz}$ $\left.\mathrm{CDCl}_{3}\right): \delta 154.4,118.3,113.7,82.7,80.2,70.1,31.9,29.5,26.0,23.0,14.4$.

General Procedure for the Preparation of P1, P2, and P3. Sonogashira polycondensations were conducted in the presence of $4 \% \mathrm{Pd}\left(\mathrm{PPh}_{3}\right)_{4}$ and $4 \% \mathrm{CuI}$ in the solution of diisopropylamine/toluene $(1: 2)$ at $60^{\circ} \mathrm{C}$ for 24 hours and then subjected to a $\mathrm{CHCl}_{3} / \mathrm{H}_{2} \mathrm{O}$ workup. The combined organic phase was washed with water $\mathrm{NH}_{4} \mathrm{OH}$ (50\%) twice, water twice, and brine, and then dried over $\mathrm{MgSO}_{4}$. The solution was removed in vacuo, and the residue was redissolved in a minimum of $\mathrm{CHCl}_{3}$ and the solution was reprecipitated in methanol twice. The mixture was filtered, and dried under vacuum at room temperature. Polymer $\mathbf{1} \& \mathbf{2}$ were prepared from M4 and 1,4-diiodobenzene. For polymer 1, in order to control the molecular weight, $10 \%$ iodo-benzene was added as end-caps. Polymer 3 was synthesized from M2 and M4.

P1\&P2: 0.52 g (yield 78\%) for P1 and 0.46 g (yield 81\%) for P2, respectively. ${ }^{1} \mathrm{H}$ NMR $\left(\mathrm{CDCl}_{3}, \mathrm{ppm}\right): \delta 7.54(\mathrm{~d}, 2 \mathrm{H}), 7.34(\mathrm{~d}, 2 \mathrm{H}), 7.02-7.00(\mathrm{~m}, 2 \mathrm{H}), 4.03(\mathrm{~m}, 4 \mathrm{H})$, $1.85(\mathrm{br}, 4 \mathrm{H}), 1.52(\mathrm{br}, 4 \mathrm{H}), 1.36(\mathrm{br}, 8 \mathrm{H}), 0.89(\mathrm{~m}, 6 \mathrm{H}) .{ }^{13} \mathrm{C} \mathrm{NMR}\left(\mathrm{CDCl}_{3}, \mathrm{ppm}\right): \delta$ 
$153.68,133.60,128.20,117.00,114.81,94.97,84.97,70.90,31.85,29.55,25.97$, $22.88,14.30$.

P3: $0.61 \mathrm{~g}$ (yield 76\%). ${ }^{1} \mathrm{H}$ NMR $\left(\mathrm{CDCl}_{3}, \mathrm{ppm}\right): \delta$ 7.02-6.96 (m, 2H), $4.03(\mathrm{~m}, 4 \mathrm{H})$, 1.86 (br, 4H), 1.52 (br, 4H), 1.37 (br, 8H), 0.91 (m, 6H). $\left.{ }^{13} \mathrm{C} \mathrm{NMR} \mathrm{(CDCl} 3, \mathrm{ppm}\right)$ : $\delta 154.60,117.92,115.03,101.62,70.12,32.01,29.70,26.07,23.02,14.41$.

P4: $0.42 \mathrm{~g}$ (yield 85\%). ${ }^{1} \mathrm{H}$ NMR $\left(\mathrm{CDCl}_{3}, \mathrm{ppm}\right): \delta 7.04(\mathrm{~s}, 2 \mathrm{H}), 4.12(\mathrm{t}, 4 \mathrm{H}), 2.95(\mathrm{t}$, 4H), $2.70(\mathrm{q}, 8 \mathrm{H}), 1.08(\mathrm{t}, 12 \mathrm{H}) .{ }^{13} \mathrm{C} \mathrm{NMR}\left(\mathrm{CDCl}_{3}, \mathrm{ppm}\right): \delta 153.8,117.5,114.6,91.9$, $68.8,52.1,48.4,12.6$

Scheme S1. Synthetic Routes for Monomers and Polymer 1-3
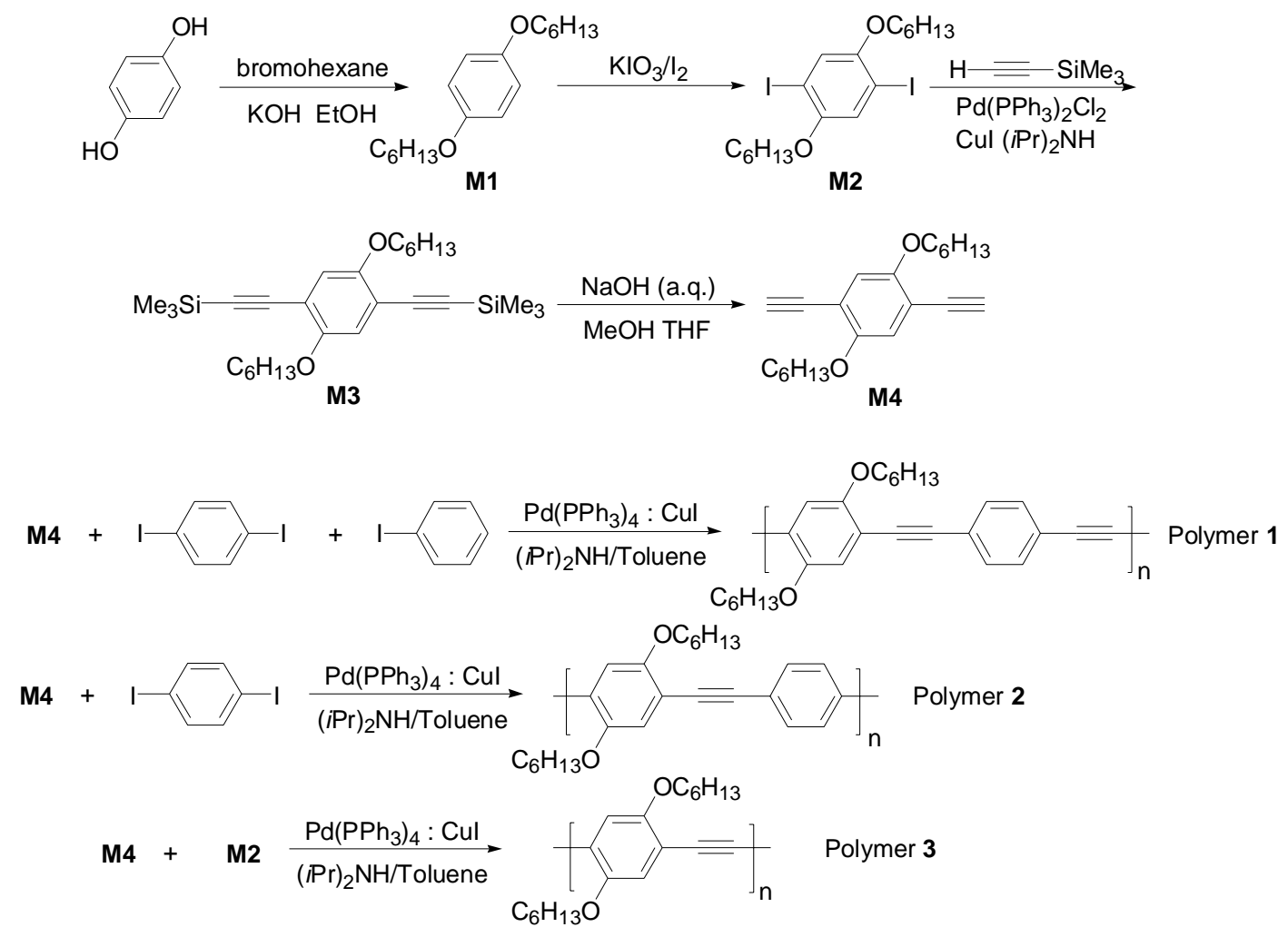

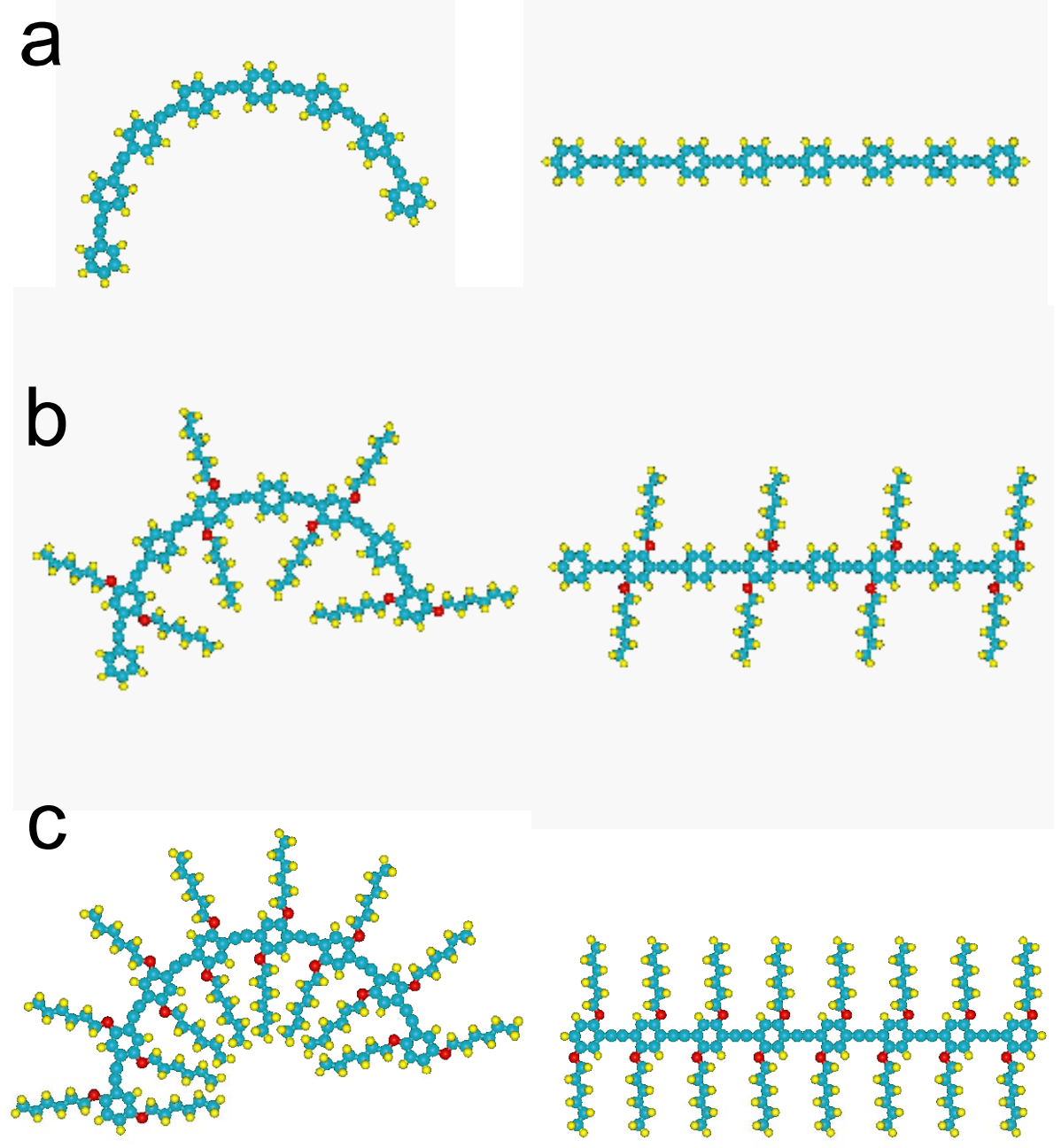

Figure S1. Simulated molecular models for the hair pin folding with a diameter of 3.2 $\mathrm{nm}$. The system energy of the folded molecule (left column) is 18.75, 14.68 and 16.29 $\mathrm{kcal} / \mathrm{mol}$ higher in compare with that of the linear conformation (right column). 

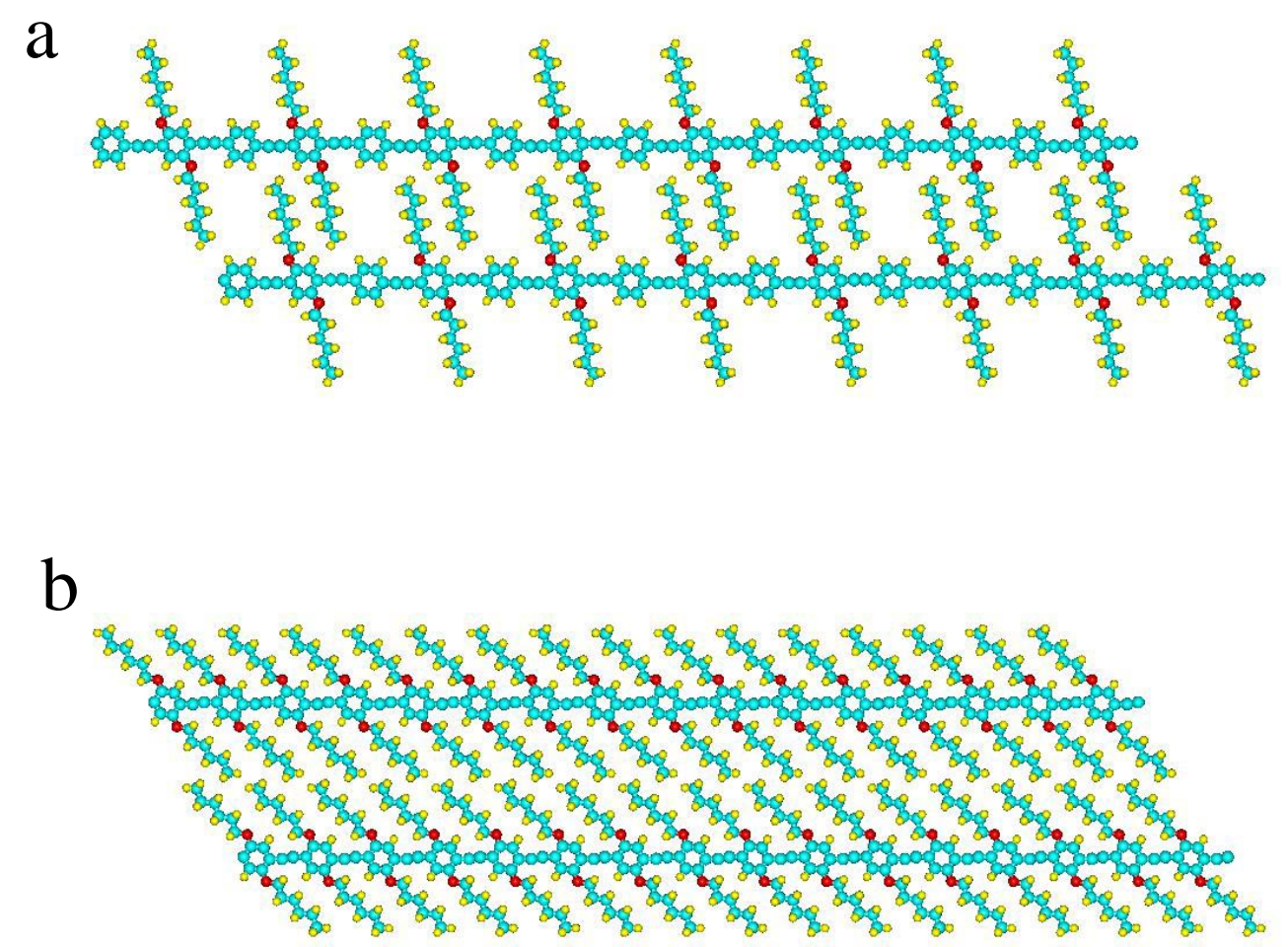

Figure S2. Optimized model of interdigitated and lamellae phase arrangement of polymer 1 (a) and 3 (b), respectively. The intermolecular interactions calculated are 5.846 and $3.047 \mathrm{kcal} / \mathrm{mol}$ per repeating unit, respectively. For a polymer chain with the length of $11 \mathrm{~nm}$, the interaction energy is calculated to be 46.77 and $48.75 \mathrm{kcal} / \mathrm{mol}$, only with a difference of about $5 \%$.

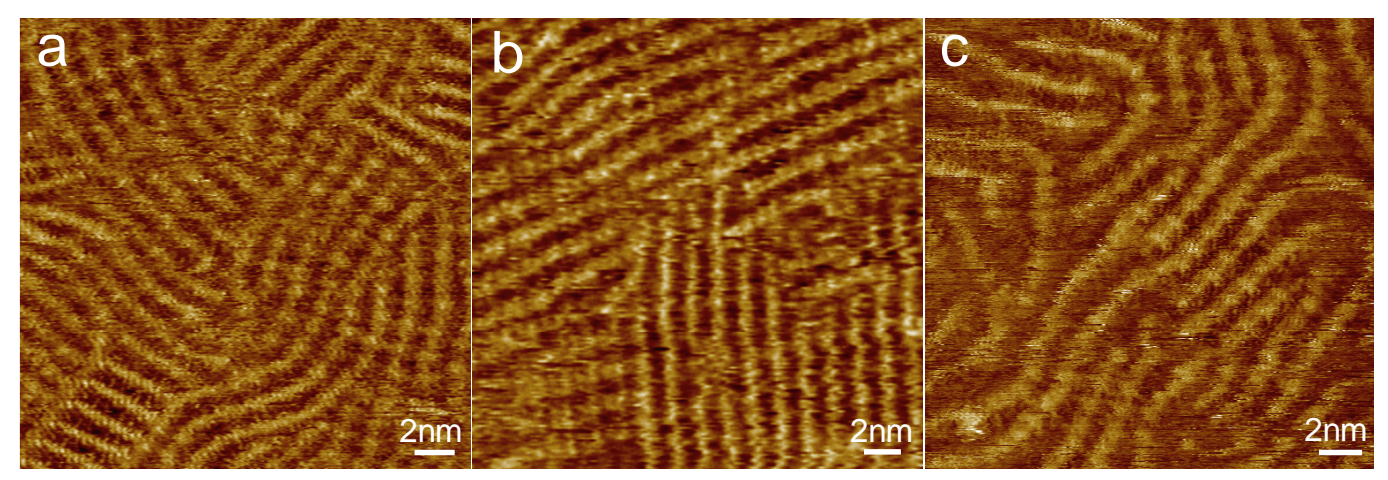

Figure S3. Comparing of the polymer chain conformation of PPEs with low and high side chain concentration. (a) polymer 1, (b) polymer 2 and (c) polymer 3 . There is more apparent variation of the interchain distance in the assembly of polymer 3. 


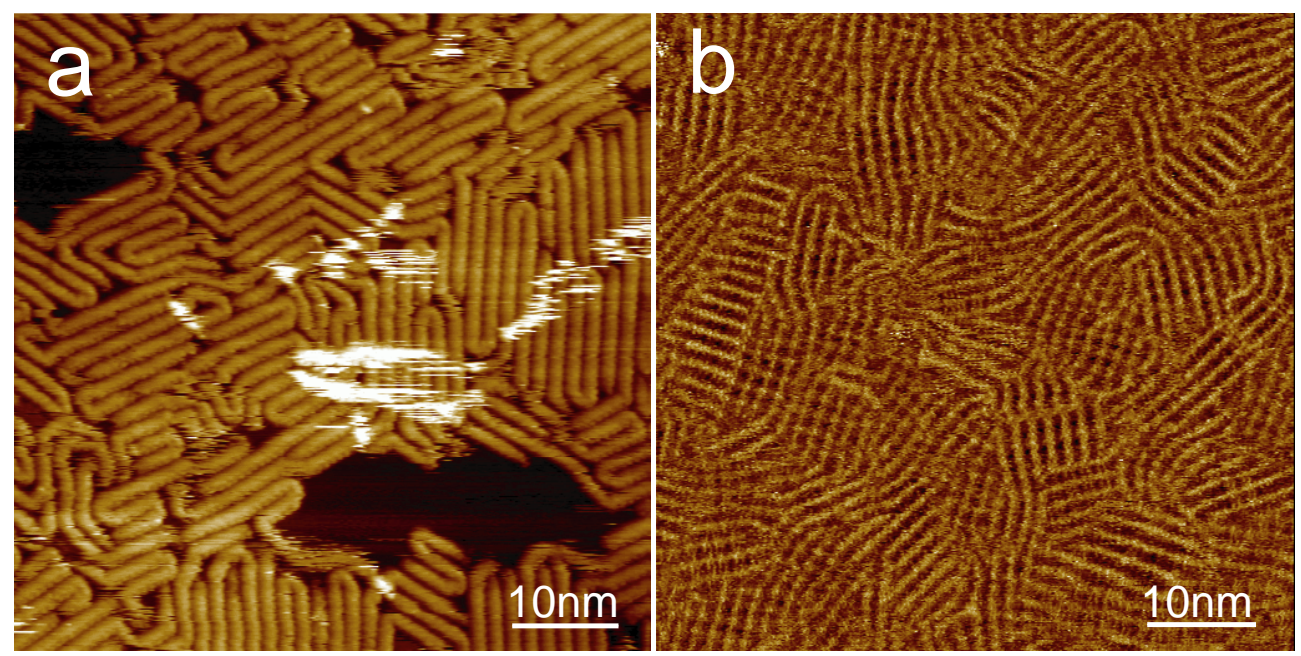

Figure S4. STM images obtained on the assembling layer of the poly(3-octylthiophene) and polymer 1 , respectively. One thing noticeable is that only specific folding angles $0^{\circ}, 60^{\circ}$ and $120^{\circ}$ could be formed in the assembling layer of poly(3-octylthiophene), while for PPE, the chain folding is not limited by these specific angles, indicating the effect of the backbone rigidity.

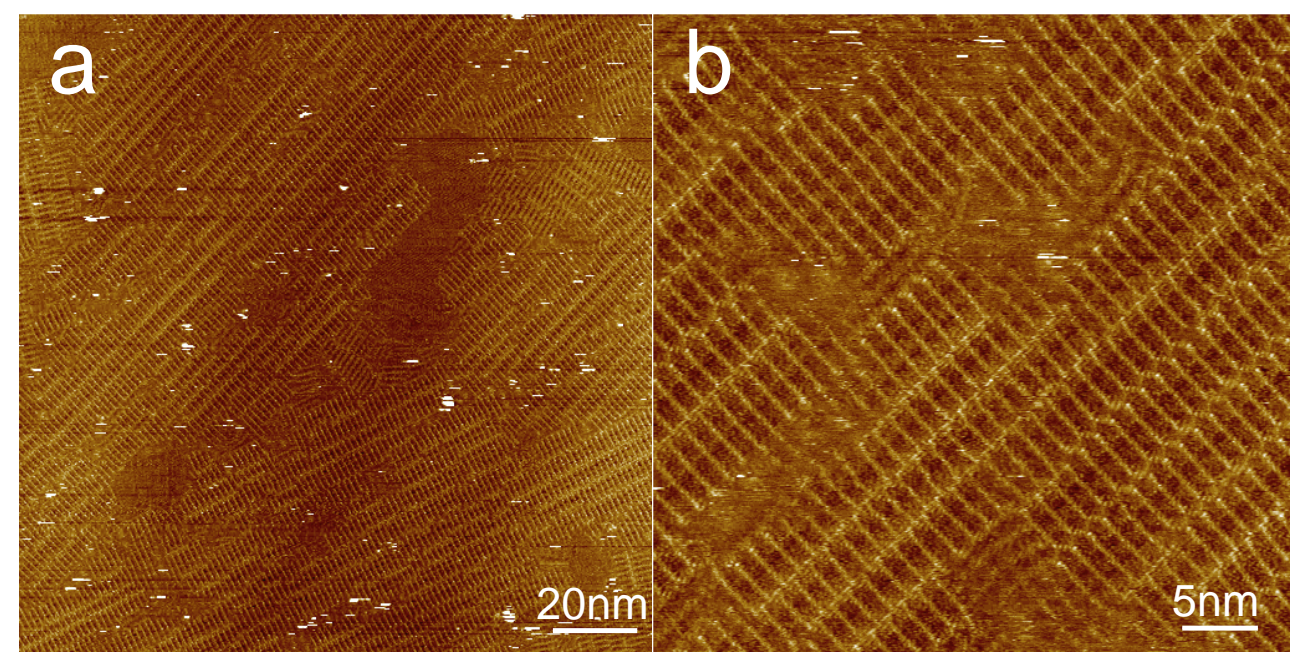

Figure S5. Assembling structure of polymer 2 obtained on the interface of phenyloctane/graphite. The assembling layer is composed mostly by oligomers of different length. The solution was prepared by dissolving excessive amount of solid polymer 2 into phenyloctane and the assembling layer is formed by depositing a drop of the upper clear solution on the freshly cleaved graphite. The STM results indicate the molecules with smaller molecular weight more easily dissolves in the phenyloctane. 